\title{
Microstructural Control of Pyrolytic Carbon Layer Deposited from Methane by Isotropic Chemical Vapor Infiltration
}

\author{
Young-Seok Jeong*, Kyoon Choi (iD)*,; and Ho Gyu Yoon** \\ *Icheon Branch, Korea Institute of Ceramic Engineering and Technology, Icheon 17303, Korea \\ **Department of Materials Science and Engineering, Korea University, Seoul 02841, Korea
}

(Received April 19, 2019; Revised May 8, 2018; Accepted May 9, 2019)

\begin{abstract}
Pyrolytic carbon (PyC) layers were deposited using methane. The PyC layer deposited with 5\% methane showed highly textured graphite, while that deposited using $100 \%$ methane showed low textured graphite. The degrees of anisotropy of the carbon layers were measured using an X-ray diffractometer, a transmission electron microscope, and a Raman spectroscope, and the results were compared with those reported previously. The orientation angles obtained from the fast Fourier transformation of the high-resolution transmission electron microscopy images and the $I_{D} / I_{G}$ intensity ratios obtained from the Raman spectra were used to evaluate the anisotropy of the PyC layers.
\end{abstract}

Key words: Ceramic matrix composite, Chemical vapor infiltration, Pyrolytic carbon, Transmission electron microscope, Raman spectroscope

\section{Introduction}

$\mathrm{S}$ iC-based ceramic matrix composites (CMCs) exhibit excellent fracture toughness, high strength, and excellent oxidation/ablation resistance at high temperatures ${ }^{1,2}$ and have been intensively investigated for structural components like shrouds, vanes and blades for aerospace applications. ${ }^{3)}$ The excellent mechanical properties of CMCs can be mainly attributed to the energy absorption at the interface between the fiber and the matrix, which is induced by various mechanisms such as crack deflection, bridging, and pull out of the fibers. Therefore, the fiber/matrix interface should exhibit an optimum bonding strength with low shear strength at the operating temperature. The bonding strength between the fiber and the matrix can be controlled by adjusting the thickness and/or microstructure of the interface layer. ${ }^{4,5)}$ Pyrolytic carbon (PyC) with low bond energy along c-axis is mainly deposited as the interface layer via chemical vapor deposition using methane or propane as the precursors.

The crystal structure of PyC layers depends on the deposition conditions such as temperature, pressure, residence time, and flow rate. ${ }^{6}$ In most of the cases, the layers show a turbostratic structure, which is unfavorable for applications in structural components. ${ }^{7}$ Controlling the microstructure of the PyC layer in CMCs is one of the major technical

Corresponding author : Kyoon Choi

E-mail : knchoi@kicet.re.kr

Tel : +82-31-645-1456 Fax : +82-31-645-1493

ORCID

https://orcid.org/0000-0001-8211-3372 issues in CMC. Lieberman et al. classified the crystal structure of PyC layers as: rough laminar (RL), smooth laminar (SL), and isotropic (ISO) on the basis of their extinction angles determined using a polarization light microscope. ${ }^{8)}$ Vallerot et al. reported that the classification of $\mathrm{PyC}$ is controversial because of the use of inappropriate tools for examining the PyC structure and proposed a two-dimensional diagram to differentiate the regenerative laminar structure from RL with the aid of both structural and textural parameters obtained through Raman and transmission electron microscopy (TEM) analyses, respectively. ${ }^{9)}$ Meadows et al. used selected area diffraction patterns (SAEDPs) to classify the microstructure of PyC layers as low-texture (LT), medium-texture (MT), and high-texture (HT) ${ }^{10)}$ SiC-based composites with anisotropic PyC structures exhibit improved mechanical properties such as toughness and strength. ${ }^{11-14)}$

In this study, we carried out the microstructural control of PyC layers deposited using methane as the raw material and quantified their degree of anisotropy using Raman spectroscopy, X-ray diffraction (XRD), and TEM.

\section{Experimental Procedure}

\subsection{Infiltration conditions}

The carbon fiber preforms used in this study were manufactured in Daeyang (Daeyang Industries Co., Ltd, Korea, Korea). The needle-punched (2.5D) preforms had a diameter of $50 \mathrm{~mm}$, thickness of $10 \mathrm{~mm}$, and density of $0.45 \mathrm{~g} / \mathrm{cc}$. The $\mathrm{PyC}$ layers were deposited in an isothermal chemical vapor infiltration system equipped with a dry pump and MFCs. The inlet structure near the hot zone has been described elsewhere. ${ }^{15)}$ The precursors for the PyC layers were hydro- 
gen gas and methane (5\% and 100\%). The temperature was fixed at $1200^{\circ} \mathrm{C}$ and the pressure of the reactor was maintained at 10 Torr using a throttle valve and a capacitancediaphragm-gauge. The flow rate of the precursors was 300 sccm and the residence time calculated from the estimated hot zone was $1.3 \mathrm{~s}$.

\subsection{Structural characterization}

The preforms were cut into small slices $(10 \mathrm{~mm} \times 3 \mathrm{~mm} \times$ $1 \mathrm{~mm})$. The thickness of the PyC layers was determined using a scanning electron microscope (JSM-6390, JEOL, Japan). The preforms were pulverized in an agate mortar and were then sieved with a 325-mesh screen to measure the crystallinity of carbon using XRD (D/MAX 2500, Rigaku, Japan). The powders were mixed with a standard silicon powder and the $2 \theta$ range and scan speed used for the measurements were $20-30^{\circ}$ and $1 \% \mathrm{~min}$, respectively. A divergence slit of $1 / 2^{\circ}$, scattering slit of $1 / 2^{\circ}$, and receive slit of $0.15 \mathrm{~mm}$ were used to reduce the signal-to-noise ratio. ${ }^{16)}$

A transmission electron microscope (Tecnai G2 F30 STwin, AP Tech, USA) with a point-resolution of $0.2 \mathrm{~nm}$ was used to examine the carbon anisotropy of the layers. The inter-planar spacing and orientation angles (OAs) of the PyC layers were determined from their radial intensity profiles and their azimuthal projection with the fast Fourier transformation (FFT) of the corresponding high-resolution TEM (HRTEM) images using the method reported by Seyring et al.. ${ }^{17)}$ A Raman spectrometer (Renishaw, UK) was used to characterize the carbon arrangement of the PyC layers. The power of the laser was maintained at $<0.5 \mathrm{~mW}$ to avoid heating of the specimen.

\section{Results and Discussion}

\subsection{Microstructure of the PyC layers deposited on carbon preforms}

The PyC specimen deposited using 5\% $\mathrm{CH}_{4}$ and $95 \% \mathrm{H}_{2}$ was labelled as 'P5', while that deposited using $100 \% \mathrm{CH}_{4}$ was labelled as 'P100'. The microstructural examinations of $\mathrm{P} 5$ and P100 revealed that the preforms were uniformly covered with PyC (Fig. 1). The preforms could be easily penetrated by methane without blocking the surface because of its high enthalpy of formation and high diffusivity. ${ }^{18)}$ The growth rates of the $\mathrm{PyC}$ layers were calculated from their scanning electron microscopy (SEM) micrographs by determining their thickness at 20 spots, as shown in Fig. 2. The growth rate of $\mathrm{P} 100$ was 8-12 times higher than that of P5 because of its higher methane concentration. According to Bammidipati et al., high hydrogen concentrations can reduce the growth rate of PyC layers. ${ }^{19)} \mathrm{P} 100$ showed uniform thickness (irrespective of the position) as compared to P5. This indicates that the concentration of $\mathrm{CH}_{4}$ showed a gradient from the top to the bottom in the case of $\mathrm{P} 5$, where the overall reaction was controlled by the diffusion of $\mathrm{CH}_{4}$. On the other hand, P100 showed a uniform methane concentration because its overall reaction was controlled by the
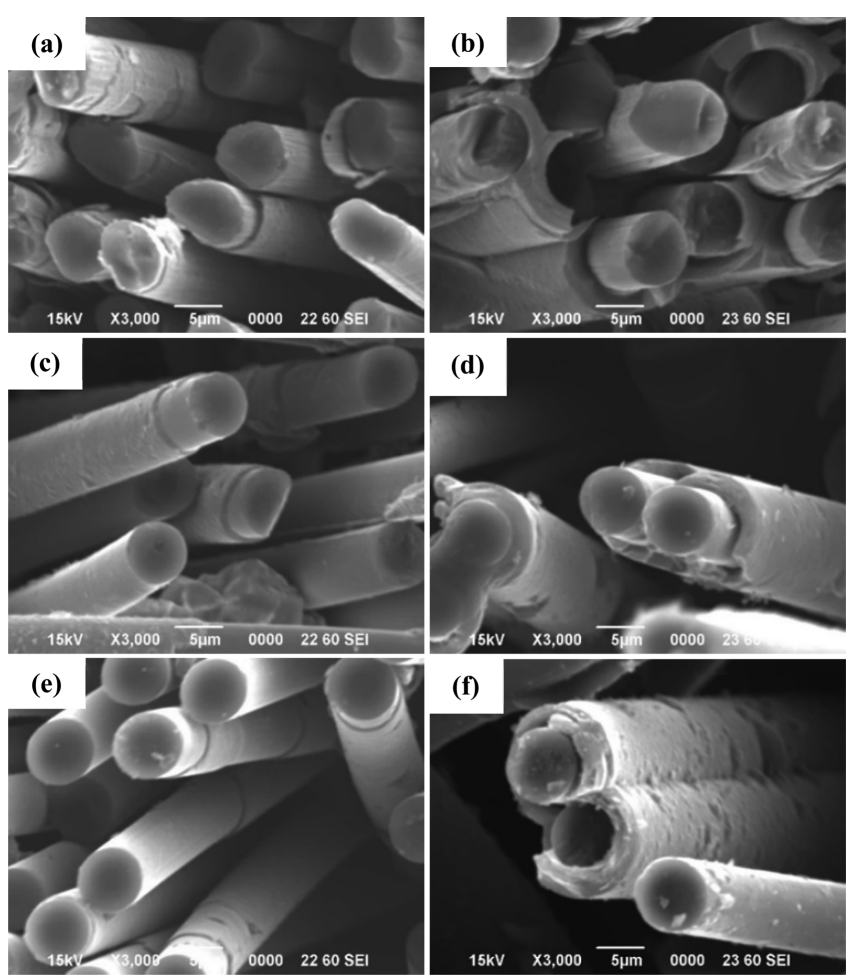

Fig. 1. SEM micrographs of the top (a,b), center (c, d), and bottom (e, f) regions of P5 (a, c, e) and P100 (b, d, f).

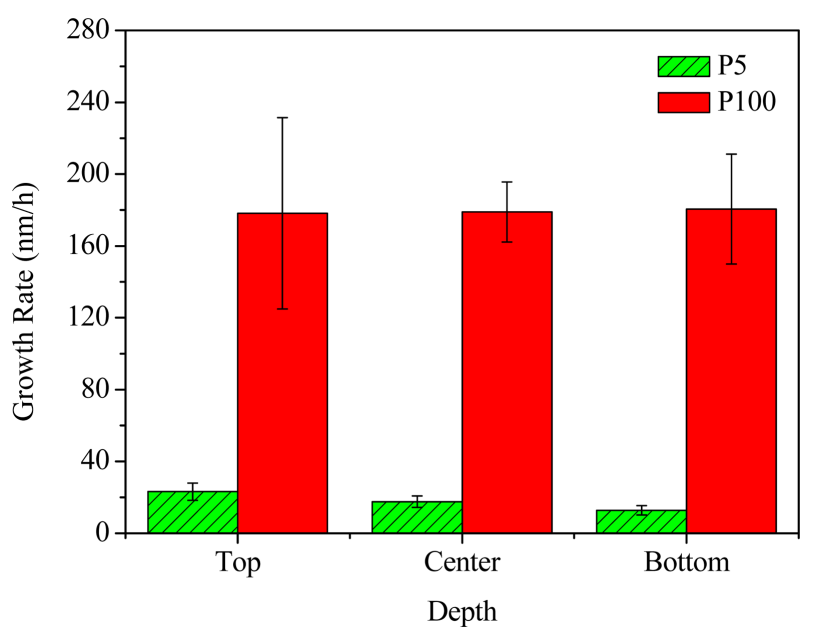

Fig. 2. Comparison of the top-to bottom growth rates of the preforms with methane concentrations of $5 \%$ (P5) and $100 \%(\mathrm{P} 100)$.

surface decomposition of $\mathrm{CH}_{4}{ }^{20)}$

\subsection{XRD analysis of the pulverized powders}

$\mathrm{XRD}$ analysis of the pulverized PyC powders was carried out to examine their crystallinity. The XRD patterns showed no crystalline phase, as shown in Fig. 3(a). The $\mathrm{d}_{002}$ of P5 and P100 was $0.345 \mathrm{~nm}$, which is higher than that of ideal graphite. ${ }^{21)}$ This indicates that the turbostratic structure of the PyC layers was formed by the generation of stacking disorders during the chemical vapor deposition growth. ${ }^{17)}$ 

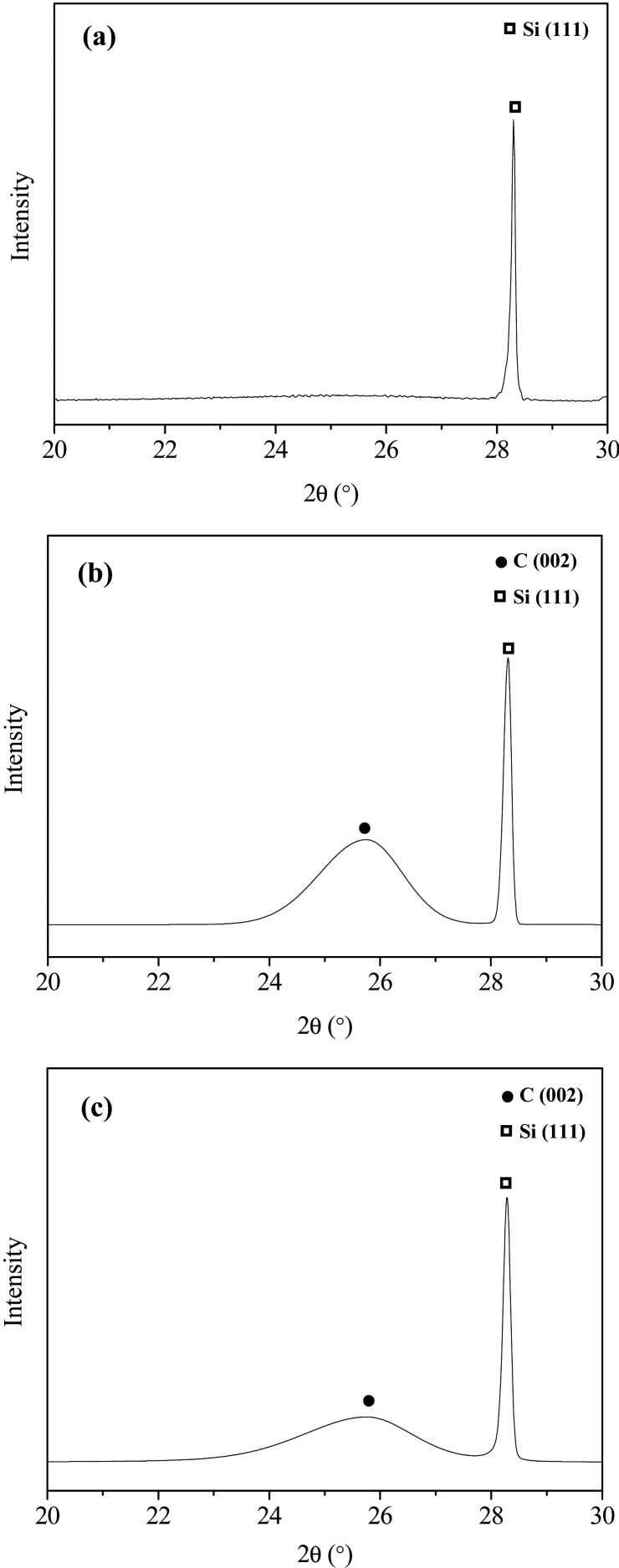

Fig. 3. XRD patterns of pulverized powders of (a) PAN-based carbon preform, (b) P5 and (c) P100.

The crystal sizes of P5 and P100 were calculated using the Scherrer equation and were found to be 4.87 and $3.59 \mathrm{~nm}$, respectively. ${ }^{22)}$ The measured full-widths at half maximum (FWHMs), asymmetric factors, and crystallite sizes of the PyC layers are listed Table 1. The asymmetric factors, which increase with the generation of stacking faults, ${ }^{23)}$ of P5 and P100 were calculated to be 1.27 and 1.4 , respec-
Table 1. Asymmetric Factors and Crystallite sizes of P5 and P100, as Determined from Their (002) Diffraction Peaks Shown in Fig. 1

\begin{tabular}{cccccc}
\hline & $\begin{array}{c}2 \theta \\
(\text { degree })\end{array}$ & $\begin{array}{c}\mathrm{D}_{002} \\
(\mathrm{~nm})\end{array}$ & $\begin{array}{c}\text { FWHM } \\
(\text { degree })\end{array}$ & $\begin{array}{c}\text { Asymmetric } \\
\text { factor }\end{array}$ & $\begin{array}{c}\text { Crystallite } \\
\text { size }(\mathrm{nm})\end{array}$ \\
\hline P5 & 25.7 & 0.345 & 1.79 & 1.27 & 4.87 \\
P100 & 25.7 & 0.345 & 2.36 & 1.4 & 3.59 \\
\hline
\end{tabular}

\section{(a)}
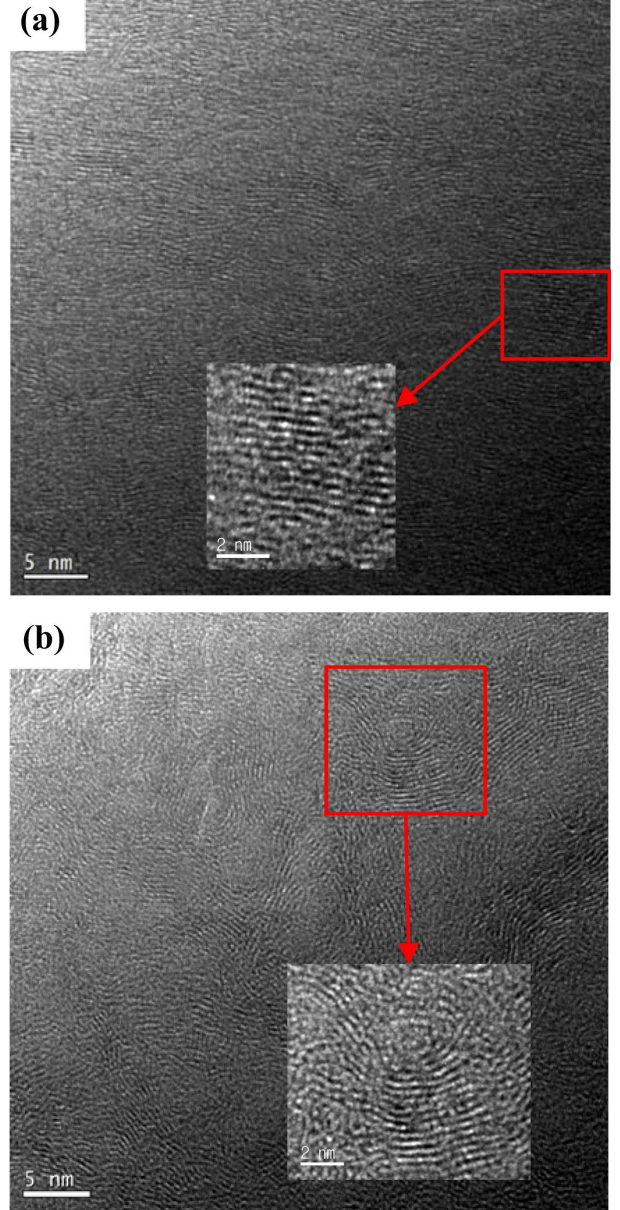

Fig. 4. TEM bright-field images of (a) P5 and (b) P100.

tively. With a decrease in FWHM values and asymmetric factors, defects like stacking faults also decrease. Thus, P5 exhibited more ideal crystal structure than P100.

\subsection{TEM analysis}

The HRTEM images of P5 and P100 with their (002) planes are shown in Fig. 4. The rectangular region exhibiting the (002) plane in Fig. 4(a) was magnified to examine its anisotropy. In the PyC layers, 15 rectangles were selected and the average distances of the (002) planes and their standard deviations were measured (Fig. 5). On the other hand, the T100 planes were curved and tortuous like a bump, as shown in Fig. 4(b). The average $\mathrm{d}_{002}$ values and their standard deviations are also shown in Fig. 5. Because of the loss of anisotropy, the deviations increased while the 


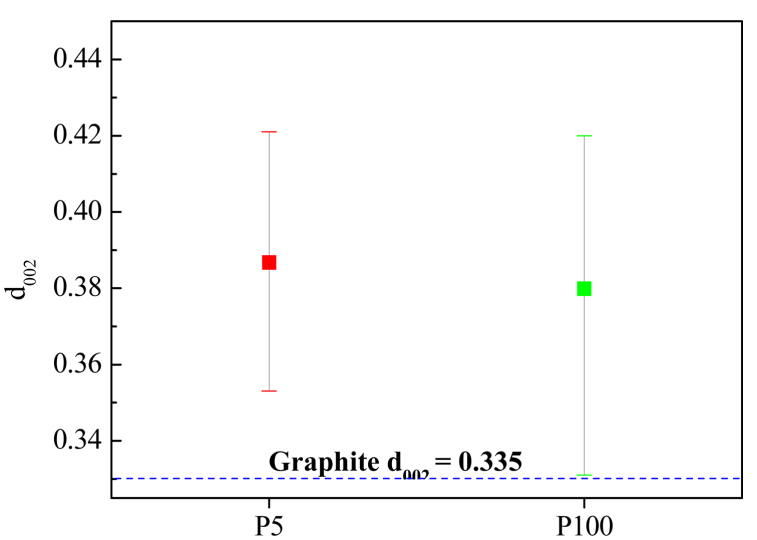

Fig. 5. $d_{002}$ values of P5 and P100.

average $d_{002}$ values remained constant. The formation of bumps can be attributed to the generation of a large number of nuclei in the gas phase, as suggested by Bourrat et $a l .{ }^{22)}$

The FFT technique is the most productive method for determining the crystal structure of a material as it can be applied to band-pass filtering and noise filtering in the reciprocal lattice space. The FFT of a material can be obtained by using the Fourier transform of its HRTEM image. FFT images are the same as SAEDs and can also be used for crystal structure analysis. This technique allows the extraction of diffraction patterns in various regions of interest such as grain boundaries and the areas having a large number of atomic defects and well-aligned atomic arrangements. ${ }^{24)}$ These two-dimensional patterns of graphene layers provide information about various structural parameters such as the orientation, interplanar distance, and curvature. Each Bragg diffraction point represents a specific interplanar distance and orientation. The distance between the center point and the reciprocal lattice space is referred to as the interplanar distance. Hence, the quantitative crystallographic analysis of specific areas can be carried out using these methods. As mentioned earlier, the statistical
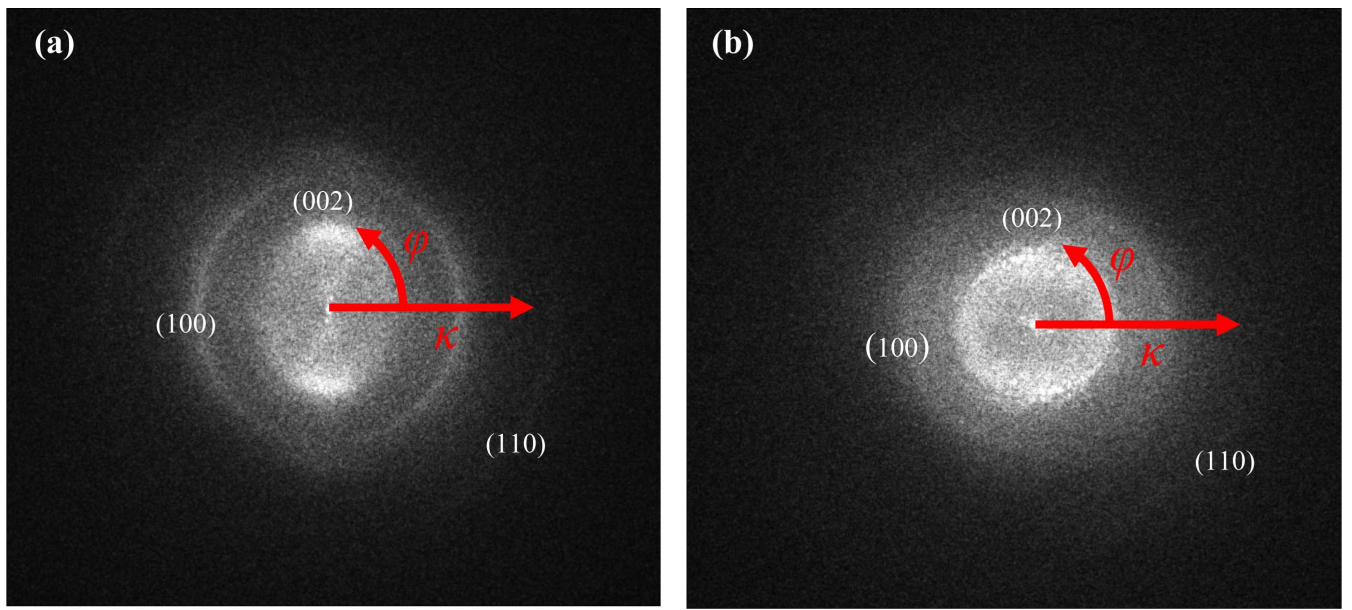

Fig. 6. FFT patterns of the TEM images of (a) P5 and (b) P100. $K$ and $F$ denote the radial distance and azimuthal angle, respectively. evaluation of the lattice parameters and crystal orientations of the PyC layers could be carried out using the FFT images shown in Figs. 4(a) and 4(b). As shown in Figs. 6(a) and 6(b), the turbostratic structure of the PyC layers consisted of not only the (002) planes but also the (100) and (110) planes, which is a characteristic of crystalline graphite. ${ }^{17)}$ The (002)
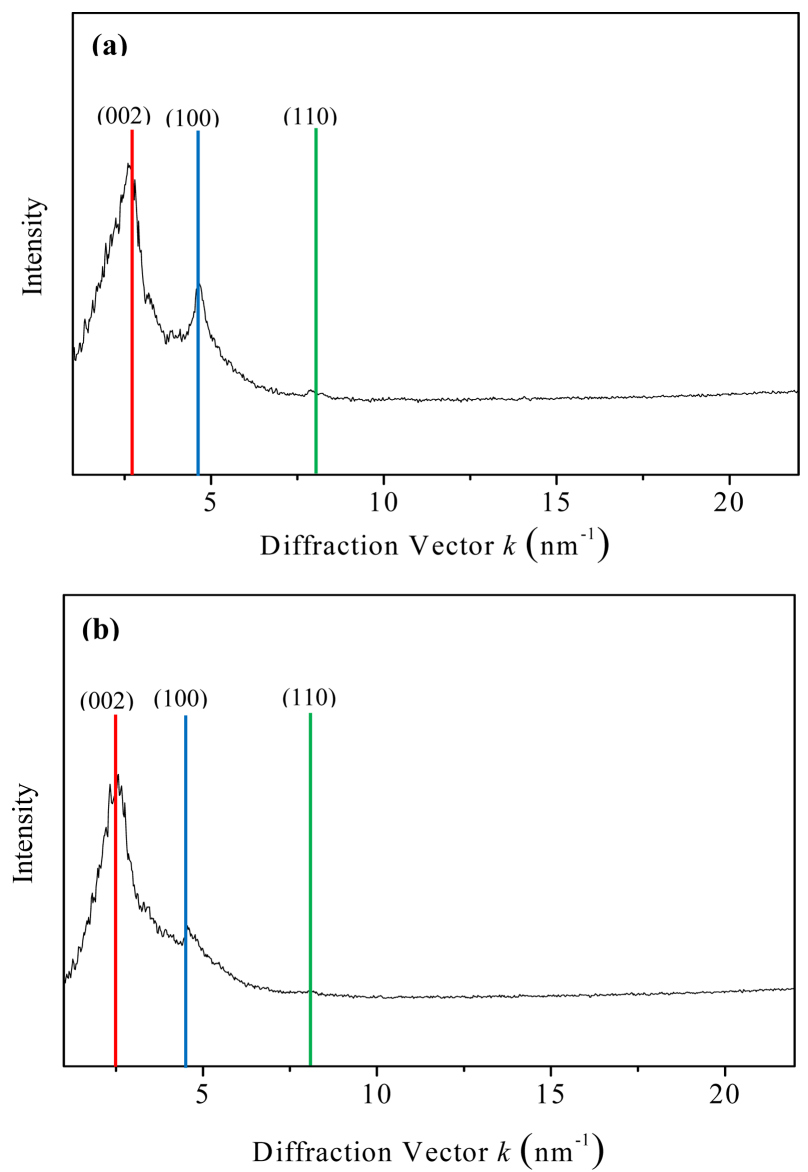

Fig. 7. Radial intensity profiles with identified maximas and the corresponding inter-planar spacings of (a) P5 and (b) P100 
Table 2. Inter-Planar Distances of the (002), (100) and (110) Planes for Graphite, P5, and P100, as Determined from Their Radial Intensity Profiles

\begin{tabular}{cccc}
\hline & $(002)$ & $(100)$ & $(110)$ \\
\hline Graphite & $0.335 \mathrm{~nm}$ & $0.213 \mathrm{~nm}$ & $0.123 \mathrm{~nm}$ \\
P5 & $0.378 \mathrm{~nm}$ & $0.214 \mathrm{~nm}$ & $0.125 \mathrm{~nm}$ \\
P100 & $0.399 \mathrm{~nm}$ & $0.217 \mathrm{~nm}$ & $0.124 \mathrm{~nm}$ \\
\hline
\end{tabular}

planes of P5 showed anisotropy, while those of P100 showed an isotropic ring pattern.

FFT images can be used for crystallographic analysis. This analysis can be carried out by determining the polar coordinates of FFT images. The coordinates of FFT images can be expressed by their diffraction vector, $\kappa$, as radial coordinates and azimuthal angle, $\varphi$, as shown in Fig. 6 . The average intensity of the azimuthal angle with respect to the diffraction coordinates can be extracted using the FFT coordinates i.e., the interplanar distance. The azimuthal projection can also axially deform $\kappa$ and $\varphi$ into two-dimensional planes, and the intensity can be determined by carrying out horizontal integration on each plane. The radial intensity curve shown in Fig. 7(a) showed sharp (100) and (110) peaks, while that in Fig. 7(b) showed small and broad (100) and (110) peaks. This indicates that P5 deposited with high
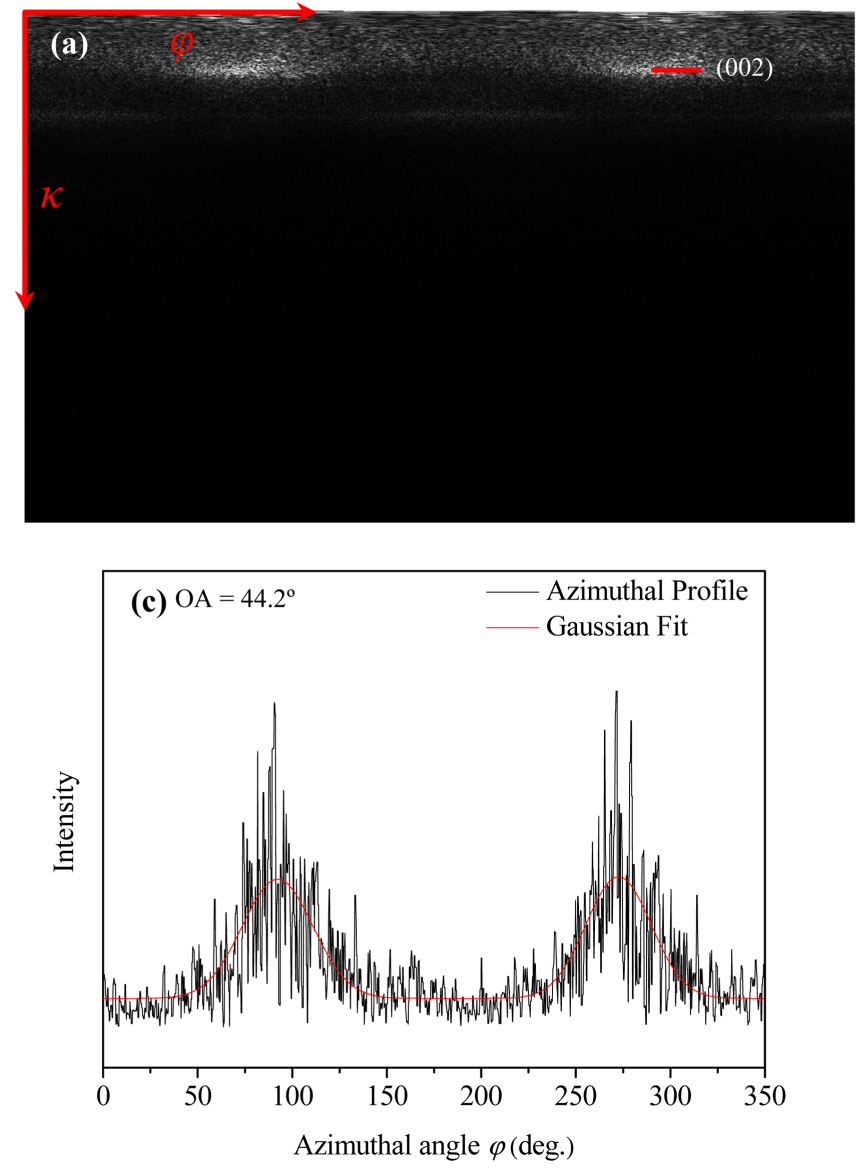

Fig. 8. Azimuthal projections of (a) P5 and (b) P100 and azimuthal profiles of the identified diffraction maxima for (c) P5 and (d) P100. planar distances of P5 and P100, as calculated from Fig. 7 under the assumption of Gaussian peaks, are listed in Table 2. Unlike P100, P5 showed lattice parameters comparable to those of graphite. This indicates that P5 is suitable for improving the toughness of CMCs owing to their good mechanical properties. The OAs of the layers were calculated by plotting the data shown in Fig. 6 to extend the intensity along the azimuthal angle of the (002) planes, as shown in Fig. 8. By comparing the azimuthal profiles of the layers with the normal ones under the Gaussian distribution of peaks, as shown in Figs. 8(c) and 8(d), the OAs of P5 and P100 were measured to be 44.2 and $118^{\circ}$, respectively.

\subsection{Raman spectroscopic analysis}

Raman spectroscopy is widely used for investigating the bonding characteristics of carbon materials owing to its nondestructive nature and high sensitivity. ${ }^{25)}$ The Raman spectra of carbon materials show their G and D peaks. ${ }^{25,26)}$ The G peak corresponds to the on-plane mode of phonon absorption at $1576 \mathrm{~cm}^{-1}$, which is a characteristic of $\mathrm{sp}^{2}$ carbon bonding. On the other hand, the $\mathrm{D}$ peak is corresponds to $\mathrm{sp}^{3}$ carbon bonding and is a characteristic of graphite. Hence, the $\mathrm{D}$ peak of PyC reflects the concentration of defects, and the $I_{D} / I_{G}$ ratio graphite-related materials is a measure of
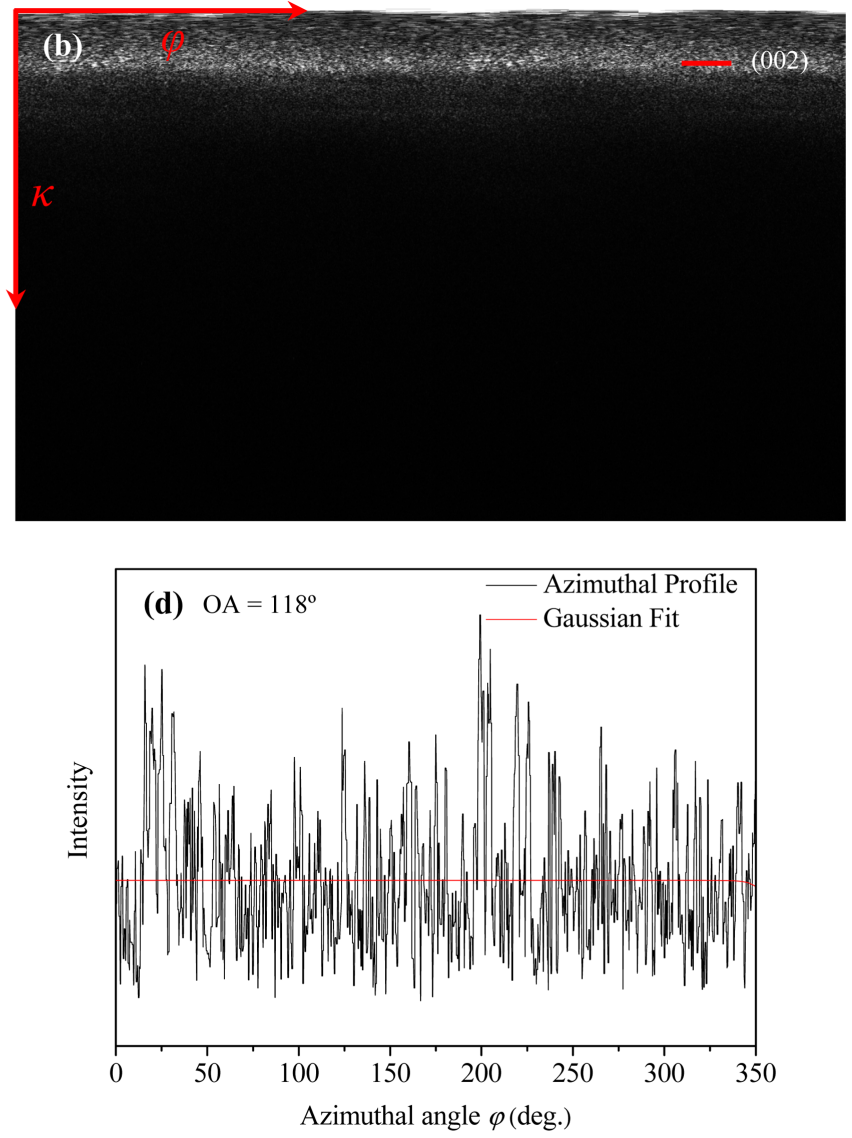

texture, while P100 deposited with low texture. ${ }^{17)}$ The inter- 

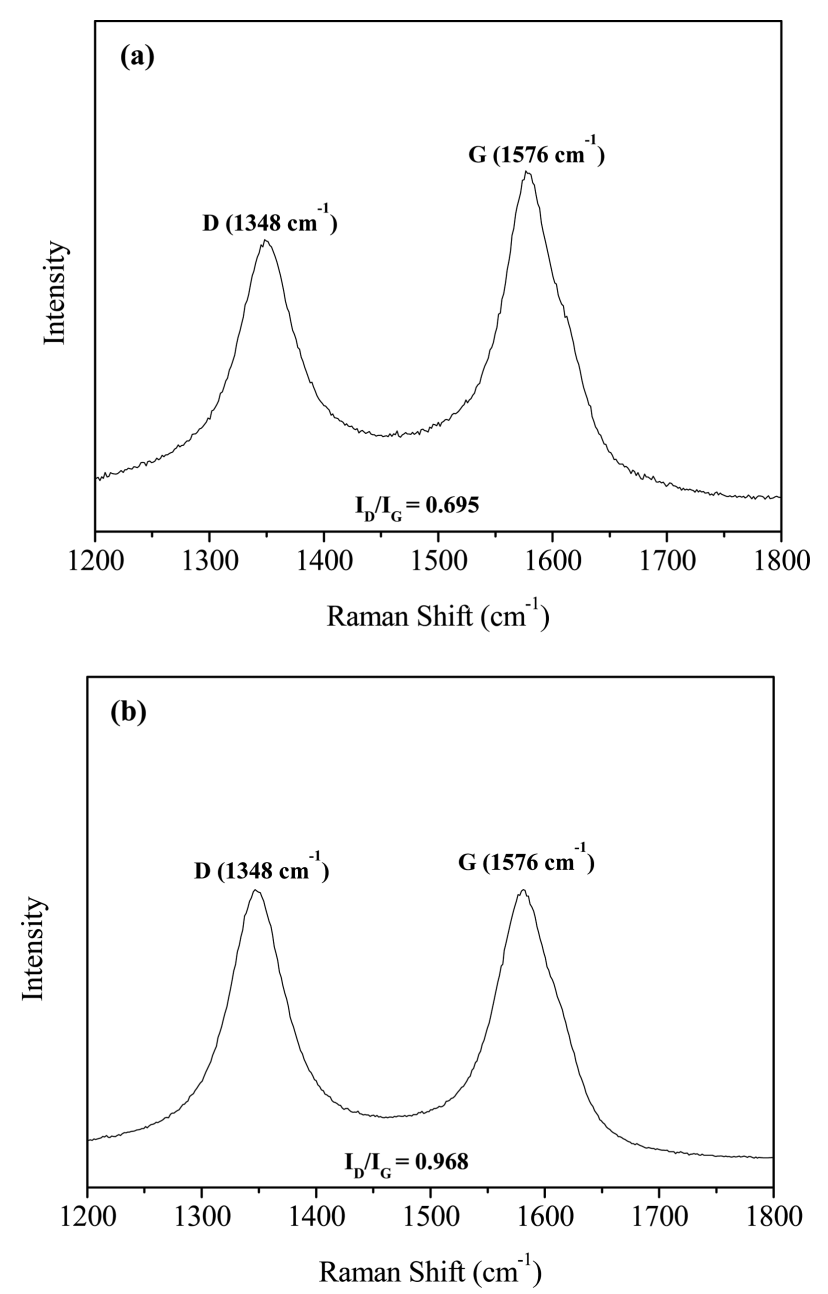

Fig. 9. Raman spectra of (a) P5 and (b) P100.

their atomistic perfection. ${ }^{25)}$ In order to compare the crystallinity of P5 and P100, their Raman spectra were recorded, as shown in Fig. 9. The $I_{D} / I_{G}$ ratios of $P 5$ and $P 100$ were measured to be 0.695 and 0.968 , respectively. This indicates that P5 showed higher crystallinity than P100.

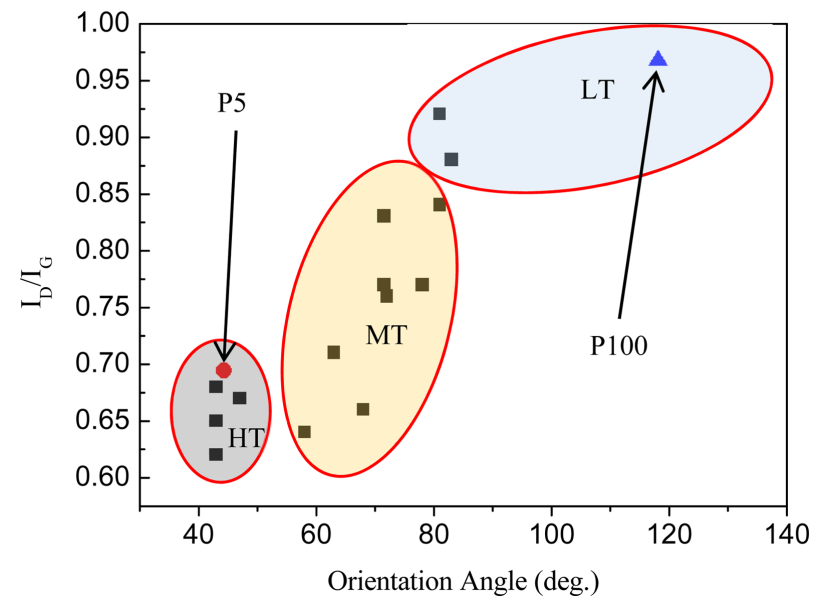

Fig. 10. $I_{D} / I_{G}$ vs. OA plots for the PyC layers.
According to Meadows et al., depending on their $\mathrm{I}_{\mathrm{D}} / \mathrm{I}_{\mathrm{G}}$ and OA, PyC layers can be classified as: HT, MT, and LT (Fig. 10). ${ }^{10)} \mathrm{P} 5$ and $\mathrm{P} 100$ were found to be HT and LT, respectively. The low methane concentration of P5 contributed to its HT structure and idealistic inter-layer microstructure. Such PyC layers show highly anisotropic inter-layers and can be applied for developing CMCs with high toughness.

\section{Conclusions}

CMCs are ceramic-based materials and are used for developing highly reliable aerospace components since they can withstand high temperatures of about $1300^{\circ} \mathrm{C}$ in air. ${ }^{27)} \mathrm{In}$ this study, we deposited anisotropic PyC layers with 5\% and $100 \%$ methane and investigated their characteristics using HRTEM, XRD, and Raman spectroscopy. The layers showed high toughness, which is desirable for developing CMCs for aerospace applications. ${ }^{28)}$ Efforts are being made to optimize the thickness of PyC layers for developing CMCs with improved properties.

\section{Acknowledgments}

This work was supported by the Materials/Components Technology Development Program of the Korea Evaluation Institute of Industrial Technology (KEIT) funded by the Ministry of Trade, Industry and Energy (MOTIE) (grant code: 10065691).

\section{REFERENCES}

1. J. Yin, H. B. Zhang, X. Xiong, J. L. Zuo, and H. J. Tao, "Ablation Properties of C/C-SiC Composites Tested on an Arc Heater," Solid State Sci., 13 [11] 2055-59 (2011).

2. N. M. Ghoniem, "High-Temperature Mechanical and Material Design for SiC Composites," J. Nucl. Mater., 191-194 515-19 (1992).

3. J. E. Grady, C. E. Smith, R. M. Sullivan, V. L. Wiesner, J. B. Hurst, S. M Arnold, D. Zhu, A. S. Almansour, R. T. Bhatt, S. Kalluri, and S. Raj, "Overview of ceramic matrix composite research at NASA Glenn Research Center," Proc. ECI Conf., Cleveland, OH, 2017.

4. W. Yang, T. Noda, H. Araki, J. N. Yu, and A. Kohyama, "Mechanical properties of several advanced Tyranno-SA fiber-reinforced CVI-SiC matrix composites," Mater. Sci. Eng., 345 [1-2] 28-35 (2003).

5. B. Reznik, M. Guellali, D. Gerthsen, R. Oberacker, and W. Hoffmann, "Microstructure and Mechanical Properties of Carbon-Carbon Composites with Multilayered Pyrocarbon Matrix," Mater. Lett., 52 [1-2] 14-9 (2002).

6. O. Feron, F. Langlais, R. Naslain, and J. Thebault, "On Kinetic and Microstructural Transitions in the CVD of Pyrocarbon from Propane," Carbon, 37 [9] 1343-53 (1999).

7. A. Udayakumar, A. S. Ganesh, S. Raja, and M. Balasubramanian, "Effect of Intermediate Heat Treatment on Mechanical Properties of SiCf/SiC Composites with BN Interphase Prepared by ICVI,” J. Eur. Ceram. Soc., 31 [6] 
1145-53 (2011).

8. M. L. Lieberman and H. O. Pierson, "The Chemical Deposition of Carbon on Carbon Fibers," Carbon, 12 [3] 233-42 (1974).

9. J. M. Vallerot, X. Bourrat, A. Mouchon, and G. Chollon, "Quantitative Structural and Textural Assessment of Laminar Pyrocarbons through Raman Spectroscopy, Electron Diffraction and Few Other Techniques," Carbon, 44 [9] 1833-44 (2006).

10. P. J. Meadows, E. Lopez-Honorato, and P. Xiao, "Fluidized Bed Chemical Vapor Deposition of Pyrolytic Carbon II. Effect of Deposition Conditions on Anisotropy," Carbon, 47 [1] 251-62 (2009).

11. S Bertrand, C Droillard, R Pailler, X Bourrat, and R Naslain, "TEM Structure of $(\mathrm{PyC} / \mathrm{SiC})_{n}$ Multilayered Interphases in $\mathrm{SiC} / \mathrm{SiC}$ Composites," J. Eur. Ceram. Soc., 20 [1] 1-13 (2000).

12. S. Bertrand, P. Forio, R. Pailler, and J. Lamon, "Hi-Nicalon/SiC Minicomposites with (Pyrocarbon/SiC) ${ }_{n}$ Nanoscale Multilayered Interphases," J. Am. Ceram. Soc., 82 [9] 2465-73 (1999).

13. S. Pompidou and J. Lamon, "Analysis of Crack Deviation in Ceramic Matrix Composites and Multilayers Based on the Cook and Gordon Mechanism," Compos. Sci. Technol., 67 [10] 2052-60 (2007).

14. M. Guellali, R. Oberacker, and M. J. Hoffmann, "Influence of the Matrix Microstructure on the Mechanical Properties of CVI-Infiltrated Carbon Fiber Felts," Carbon, 43 [9] 1954-60 (2005).

15. K. Choi and J.-W. Kim, "CFD Simulation of Chemical Vapor Deposition of Silicon Carbide in $\mathrm{CH}_{3} \mathrm{SiCl}_{3}-\mathrm{H}_{2}$ System," Curr. Nanosci., 10 [1] 135-37 (2014).

16. N. Iwashita, C. R. Park, H. Fujimoto, M. Shiraishi, and M. Inagaki, "Specification for a Standard Procedure of XRay Diffraction Measurements on Carbon Materials," Carbon, 42 [4] 701-14 (2004).

17. M. Seyring, A. Simon, I. Voigt, U. Ritter, and M. Rettenmayr, "Quantitative Crystallographic Analysis of Individual Carbon Nanofibers Using High Resolution Transmission Electron Microscopy and Electron Diffraction," Carbon,
$116347-55$ (2017)

18. E. Beerdsen, B. Smit, and D. Dubbeldam, "Molecular Simulation of Loading Dependent Slow Diffusion in Confined Systems," Phys. Rev. Lett., 93 [24] 24830-1-3 (2004).

19. S. Bammidipati, G. D. Stewart, J. R. Elliott, S. A. Gokoglu, and M. J. Purdy, "Chemical Vapor Deposition of Carbon on Graphite by Methane Pyrolysis," AIChE J., 42 [11] 3123-32 (1996).

20. P. Delhaes, Fibers and Composites; Vol. 2, pp. 118-21, CRC Press, Florida, 2003.

21. B. Manoj and A. G. Kunjomana, "Study of Stacking Structure of Amorphous Carbon by X-Ray Diffraction Technique," Int. J. Electrochem. Sci., 7 [4] 3127-34 (2012).

22. X. Bourrat, A. Fillion, R. Naslain, G. Chollon, and M. Brendle, "Regenerative Laminar Pyrocarbon," Carbon, 40 [15] 2931-45 (2002).

23. T. H. Simm, "Peak Broadening Anisotropy and the Contrast Factor in Metal Alloys," Crystals, 8 [5] 1-31 (2018).

24. Y. Kuen, R. L. V. Wal, and L. B. Andre, "Development of an HRTEM Image Analysis Method to Quantify Carbon Nanostructure," Combust. Flame, 158 [9] 1837-51 (2011).

25. Y. Kaburagi, A. Yoshida and Y. Hishiyama, "Chap.7 Raman Spectroscopy," pp. 126-50 in Materials Science and Engineering of Carbon: Characterization, Ed. by I. Michio and F. Kang, Butterworth-Heinemann, Boston, 2016.

26. A. Merlen, J. G. Buijnsters, and C. Pardanaud, "A Guide to and Review of the Use of Multiwavelength Raman Spectroscopy for Characterizing Defective Aromatic Carbon Solids: from Graphene to Amorphous Carbons," Coatings, 7 [10] 153 (2017).

27. J. Y. Park, D. Kim, H.-G. Lee, W.-J. Kim, and M. Pouchon, "Oxidation Behaviors of Si Composites Tested at High Temperature in Air by an Ablation Method," J. Korean Ceram. Soc., 55 [5] 498-503 (2018).

28. K.-M. Kim, Y. S. Hahn, S.-M. Lee, K. Choi, and J.-H. Lee, "Mechanical Properties of $\mathrm{C}_{\mathrm{f}} / \mathrm{SiC}$ Composite Using a Combined Process of Chemical Vapor Infiltration and Precursor Infiltration Pyrolysis," J. Korean Ceram. Soc., 55 [4] 392-99 (2018). 